\title{
Coupling of Arctic ozone and stratospheric dynamics and its influence on surface climate:
}

The role of CFC concentrations

Abstract ID: EGU2020-9118

Marina Friedel ${ }^{1}$, Gabriel Chiodo ${ }^{1,2}$, Stefan Muthers ${ }^{3}$, Julien Anet ${ }^{4}$, Andrea Stenke ${ }^{1}$, Thomas Peter ${ }^{1}$

${ }^{1}$ ETH Zürich, Institute for Atmospheric and Climate Science, Zürich, Switzerland

${ }^{2}$ Applied Physics and Applied Math, Columbia University, New York (NY), USA

${ }^{3}$ German Meteorological Service, Freiburg, Germany

${ }^{4}$ ZHAW School of Engineering, Winterthur, Switzerland 


\section{Coupling of Arctic ozone and stratospheric dynamics}

\section{What?}
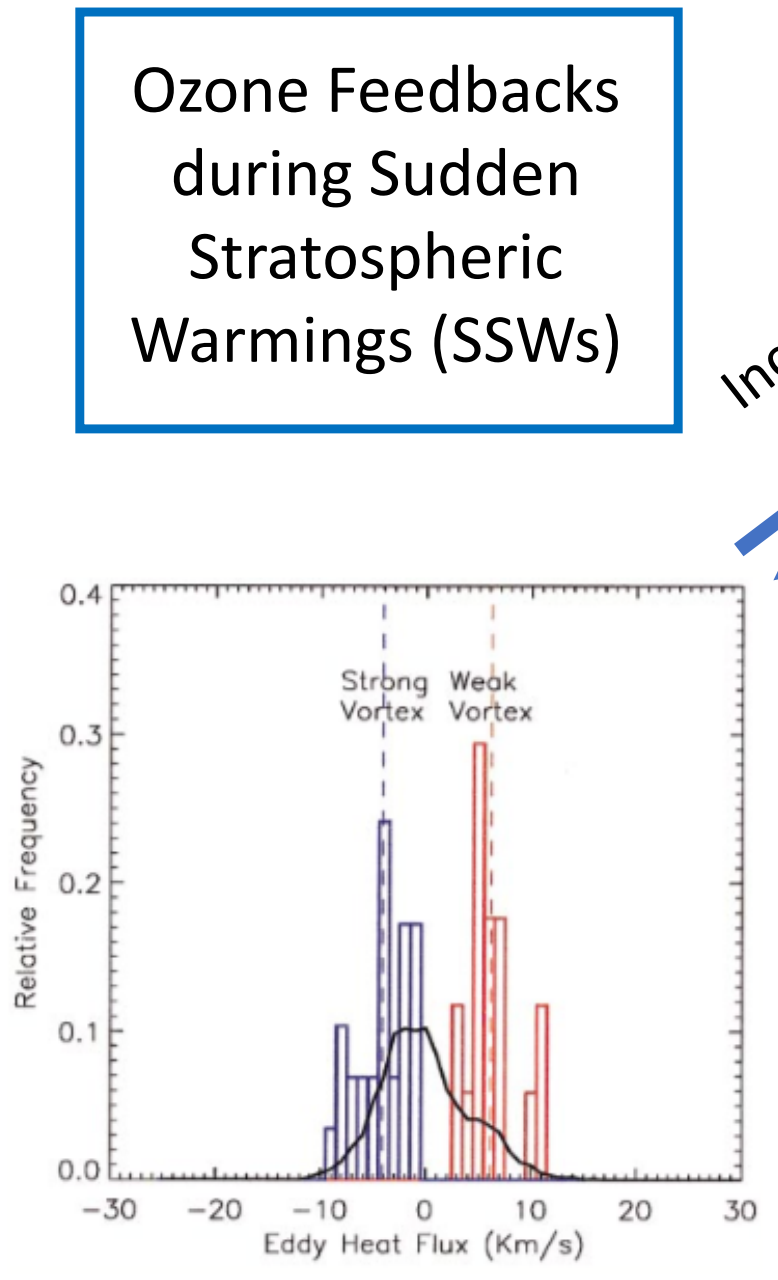

Meridional eddy heat flux, $100 \mathrm{hPa}$, Polvani and Waugh, 2004

\section{Disrupted vortex}

$10 \mathrm{hPa}, 10^{\text {th }}$ February 2018 (earth.nullschool.net)

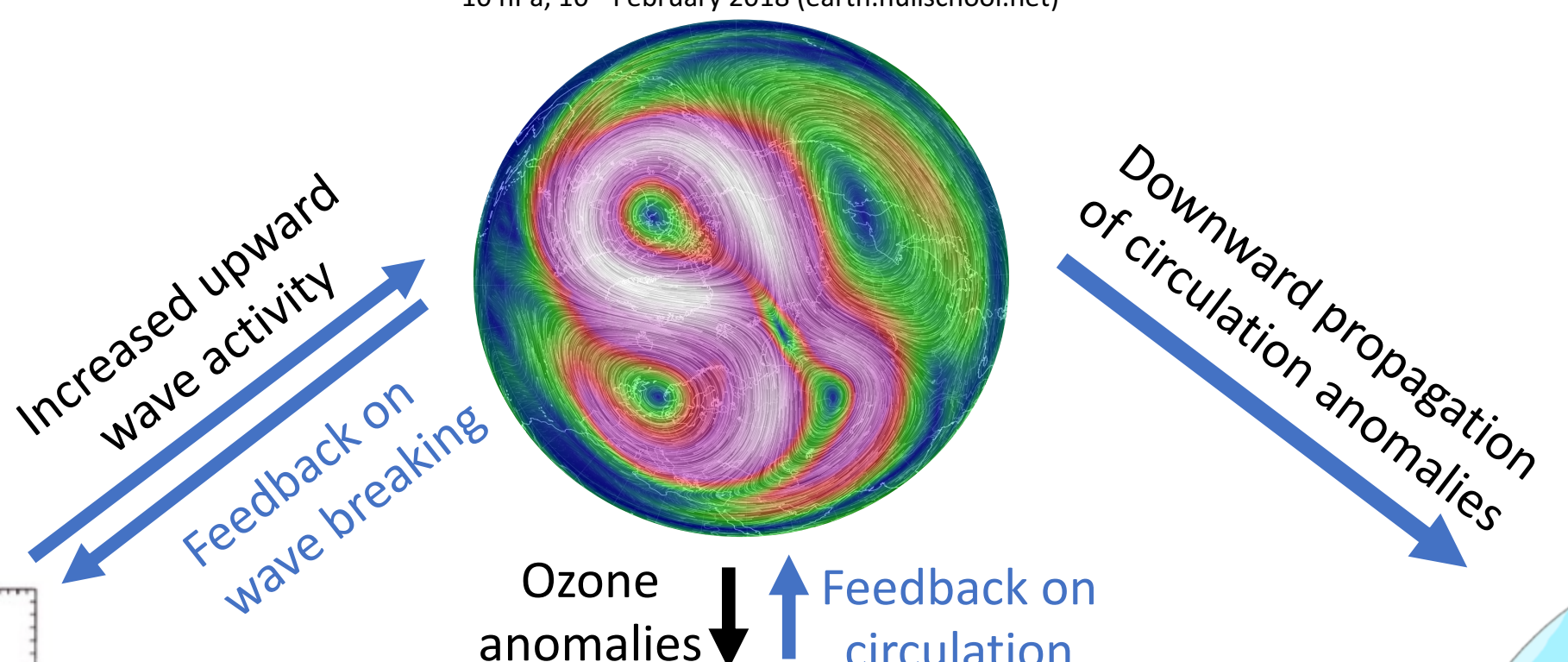

Ozone
anomalies $\downarrow$
circulation

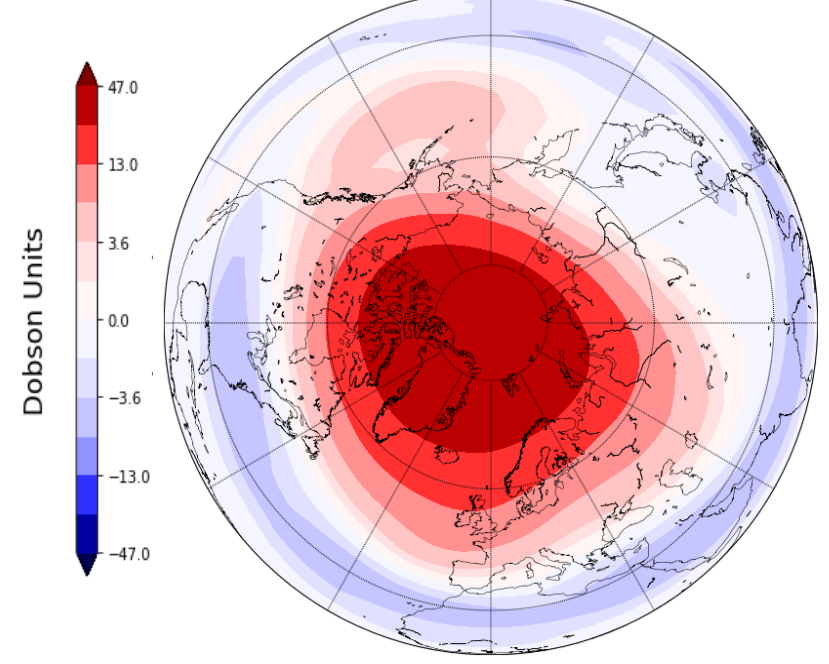

Direct radiative Impact

Surface Temperature anomalies after SSWs, Butler et al., 2017

(c) (1) 


\section{Motivation \& Method}

\section{Why?}

Understanding ozone - circulation - climate coupling could result in better seasonal predictions and long-term climate projections!

\section{How?}

- 2 Chemistry Climate Models (SOCOL \& WACCM)

- Contrasting runs with (CHEM) and without (NOCHEM) interactive chemistry (interactive vs. prescribed $\mathrm{O}_{3}$ )

- Contrasting preindustrial vs. year-2000 time slice simulations (200 years each)

- Contrasting Northern Annular Mode (NAM) indices for SSW composites 


\section{Preliminary Results - WACCM}

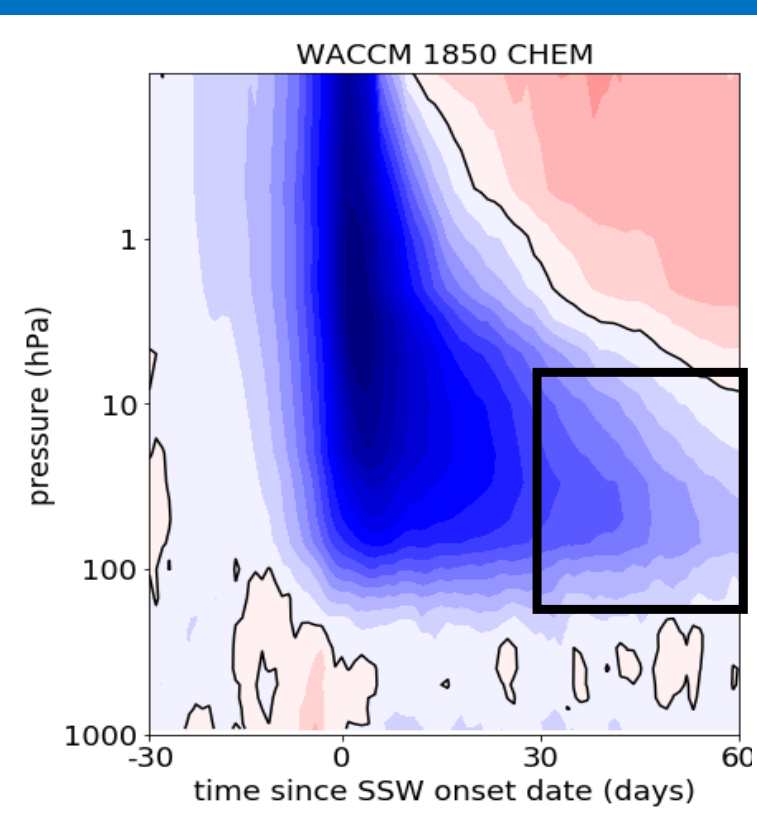

WACCM 2000 CHEM

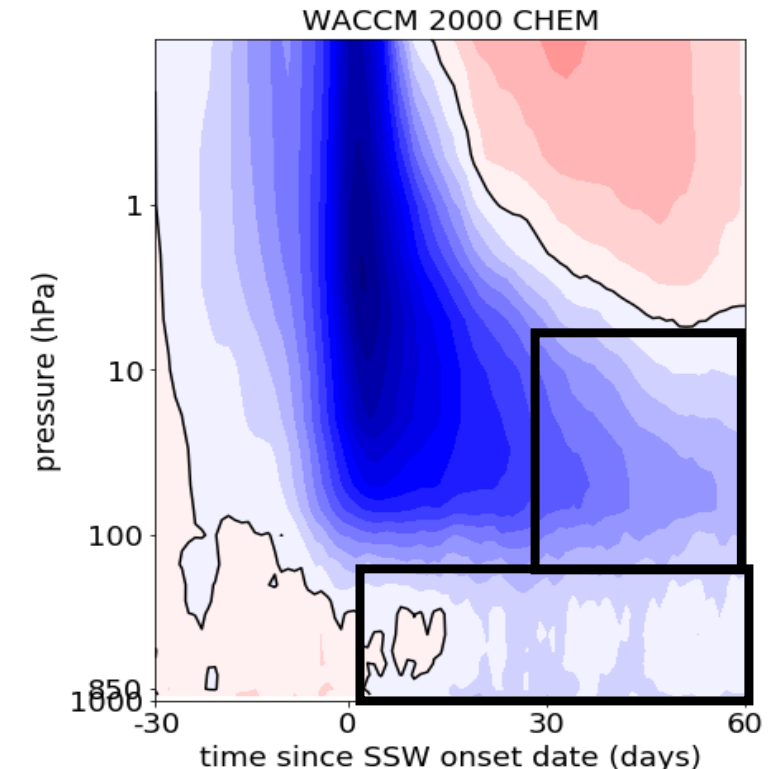

WACCM 1850 NOCHEM

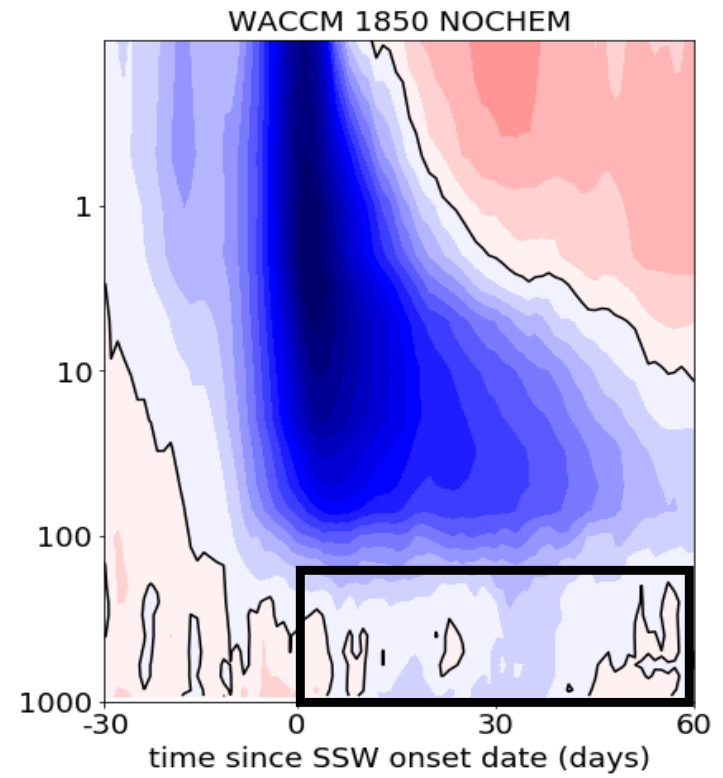

WACCM 2000 NOCHEM

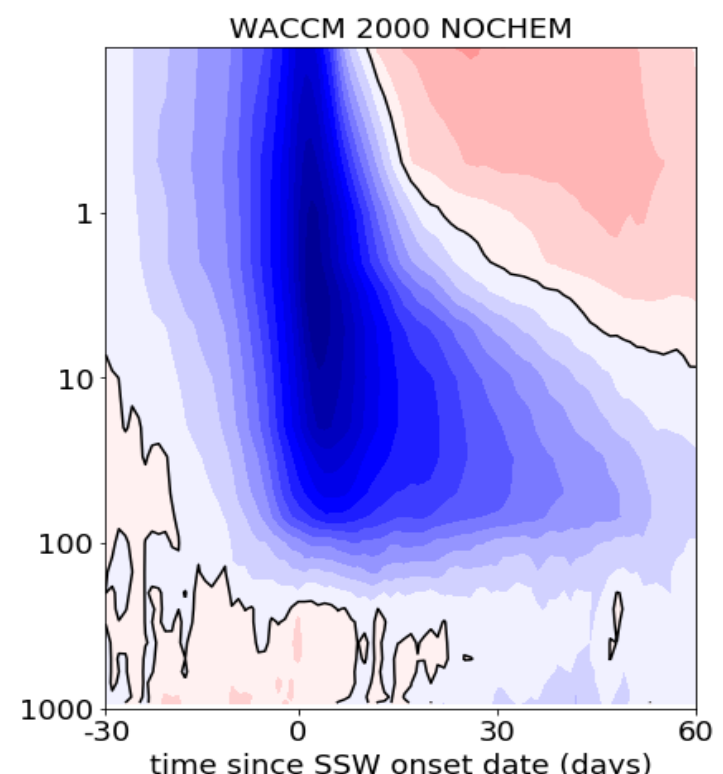

WACCM preindustrial runs:

$\rightarrow$ Stronger downward propagation in NOCHEM

$\rightarrow$ Longer lasting signal in lower stratosphere in CHEM

WACCM year-2000:

$\rightarrow$ Stronger downward propagation in CHEM

$\rightarrow$ Longer lasting signal in lower stratosphere in CHEM

(to be confirmed by SOCOL)

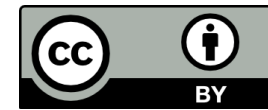




\section{Preliminary Results}

Ozone feedbacks seem to enhance the downward propagation of Sudden Stratospheric Warming signals in recent times (CHEM vs. NOCHEM year 2000).

Ozone feedbacks seem to extend and intensify the sudden stratospheric warming signature in the lower stratosphere (CHEM vs. NOCHEM).

CFC and/or GHG concentrations might influence the sign of the ozonecirculation feedback (preindustrial vs. year-2000). Internal variability might also play a role. 


\section{References}

Polvani, L.M. and D.W. Waugh, 2004: Upward Wave Activity Flux as a Precursor to Extreme Stratospheric Events and Subsequent Anomalous Surface Weather Regimes, J. Climate, 17, 3548-3554, https://doi.org/10.1175/15200442(2004)017<3548:UWAFAA>2.0.CO;2

Muthers, S., Anet, J. G., Stenke, A., Raible, C. C., Rozanov, E., Brönnimann, S., Peter, T., Arfeuille, F. X., Shapiro, A. I., Beer, J., Steinhilber, F., Brugnara, Y., and Schmutz, W.: The coupled atmosphere-chemistry-ocean model SOCOLMPIOM, Geosci. Model Dev., 7, 2157-2179, https://doi.org/10.5194/gmd-7-2157-2014, 2014.

Butler, A. H., Sjoberg, J. P., Seidel, D. J., and Rosenlof, K. H.: A sudden stratospheric warming compendium, Earth Syst. Sci. Data, 9, 63-76, https://doi.org/10.5194/essd-9-63-2017, 2017. 